\title{
Electrical conductivity of whole and shredded plant tissue
}

\author{
Nodir Eshpulatov ${ }^{*}$, Tolib Khalmuradov ${ }^{2}$, Rakhmanberdi Khalilov $^{2}$, Abdulkhay Obidov $^{2}$, and \\ Madrakhim Allanazarov ${ }^{2}$ \\ ${ }^{1}$ Tashkent Institute of Irrigation and Agricultural Mechanization Engineers, Tashkent, Uzbekistan \\ ${ }^{2}$ Tashkent State Agrarian University, Tashkent, Uzbekistan
}

\begin{abstract}
The article gives the electrical conductivity of whole and shredded plant tissue. An experimental study was made of the dependence of the resistivity value and the volume occupied by the pulp on the pressing time and specific pressures on the pulp while taking into account the amount of pressed juice. The electrical resistance $(R)$ of whole and crushed plant tissue was experimentally studied, which, when processing the results, was recalculated to the specific electrical resistance $(\rho)$ of the tissue. The specific pressure $(\mathrm{P})$ on the tissue was determined using a reference manometer, and the deformation $(\Delta \mathrm{H})$ of the sample was measured with a dial indicator.
\end{abstract}

\section{Introduction}

As a conductor of electric current with ionic conductivity, the electrophysical properties of plant tissue are quite fully characterized by the value of its electrical conductivity. By the magnitude of electrical conductivity and the nature of its dependence on certain influences (mechanical, electrical, thermal, etc.) on plant tissue, one can judge the state of the tissue and its structural elements, the efficiency of cell destruction by such influences. This, in turn, makes it possible to rationally build the technological process of electrical processing of raw materials, correctly select the parameters of this process and precisely control them.

Based on the results of studies of the dependence of the electrical conductivity of sugar beet tissue samples on axial compression, the theory of electroplasmolysis of plant materials under pressure was developed in due time [1,2]. This theory is based on the author's assumption that when the tissue is exposed to relatively low specific pressures, the intercellular spaces, usually present in plant tissue, are compressed. A state of complete internal cell contact occurs. Due to this, the electrical resistance of the tissue decreases, and the efficiency of electrical processing increases.

However, considering the peculiarities of the structure of plant tissue, its cell framework, and the structural and mechanical properties of the tissue, the basic premises of the theory of electroplasmolysis under pressure raise some doubts. It was important to determine whether the phenomenon of complete interstitial contact of cells occurs during tissue compression or whether the drop in electrical resistance is due to other reasons, for example, a decrease in

*Corresponding author: nodir_1885@mail.ru 
the contact resistance between the electrodes and the sample. Suppose the premises of this theory are correct, and in order to increase the efficiency of electrical processing, one should strive to improve the contact between cells. In that case, any methods of electrical processing of plant materials that do not include this principle will not be effective enough.

\section{Methods}

When studying the effects of an electric pulse discharge on the structures and properties of biological objects of plant origin, we used the laws of absorption of energy by matter. Changes in anatomical and ultrastructural structures were studied by microscopic observation. Evaluation of the biological state of the material was ca and the method of electrical conductivity. Experimental studies were carried out on a specially designed stand using the general methodology for conducting and processing an experiment and the mathematic experiments.

\section{Results and Discussion}

To clarify what has been said, we carried out experiments on axial compression of cylindrical apple samples. The experiments were carried out on samples $28 \mathrm{~mm}$ in diameter and 10 and $5 \mathrm{~mm}$ in height. To determine the influence of the physiological state of the tissue on the value of its electrical resistivity, experiments were carried out on samples of fresh and old apples.

The prepared sample was placed in a device for compression between electrodes isolated from the body and connected to a bridge circuit for measuring electrical conductivity. When the sample was compressed, its electrical resistance (R) was recorded, which, when processing the results, was recalculated to the specific electrical resistance $(\rho)$ of the tissue. The specific pressure $(\mathrm{P})$ on the tissue was determined using a reference manometer, and the deformation $(\Delta \mathrm{H})$ of the sample was measured with a dial indicator.

Figure 1 shows typical dependences of the electrical resistivity of apple tissue samples on the specific pressure on the sample. Curve 1 is plotted according to the data of experiments with fresh apple samples $10 \mathrm{~mm}$ high. Curve 3 - for samples of the same apples, but $5 \mathrm{~mm}$ high. Experiments with samples of stale apples are illustrated by curve 2 . In this case, the height of the samples was $10 \mathrm{~mm}$.

Experiments to determine the resistivity of apple tissue samples during axial compression showed that there is a significant decrease in the value of resistivity in the initial period of compression. Such a decrease is observed until the specific pressures of the order of 2-2.5 kgf/ $/ \mathrm{cm}^{2}$ are reached, which corresponds to point A. A further increase in pressure for apple samples has practically no effect on the resistivity, and for samples from an old apple, a slight decrease in this value is observed. Point $\mathrm{C}_{1}$ corresponds to the beginning of the destruction of the cellular framework of the tissue and its structural elements. At this pressure, the tensile strength of the fabric is reached, and it collapses. 


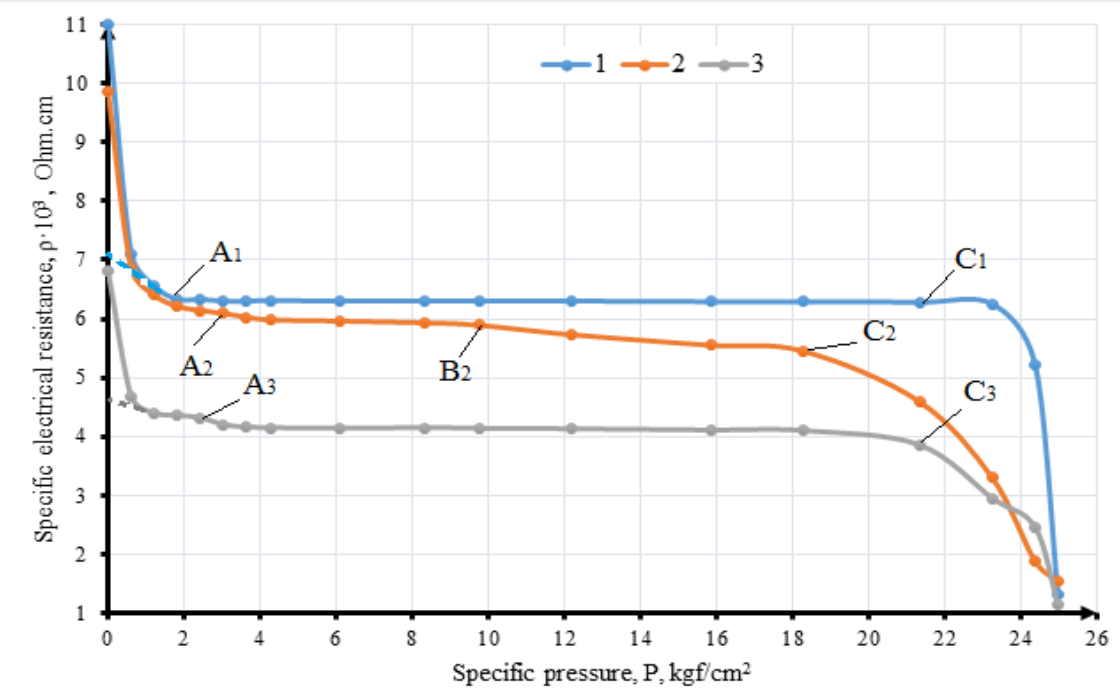

Fig. 1. The dependence of the electrical resistivity of apples on pressure: 1 and 3 are samples of fresh apples; 2 are stale apples. Sample height, in mm: 1 and 2 - 10; 3-5 (explanations in the text).

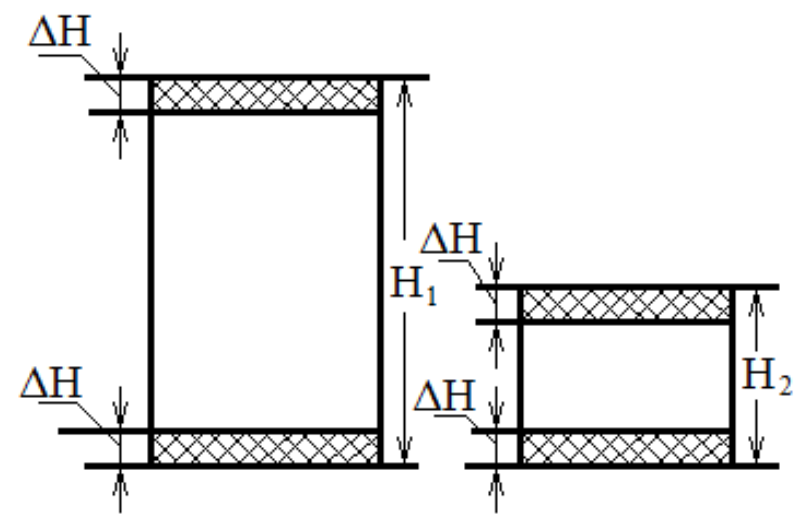

Fig. 2. Calculation scheme (Explanations in the text)

In fig. 1, the dotted line shows how the initial part of the graph changes when several drops of juice of the same apple from which the sample was cut are added under the electrodes. By improving the contact between the electrodes and the sample surface, the initial value of the resistivity decreases without any increase in pressure. Therefore, one cannot speak of the disappearance of the intercellular glands during tissue compression and a decrease in resistivity due to this. The intercellular spaces remain until reaching specific pressures corresponding to point $\mathrm{C}$. In this case, there is only an improvement in the contact between the electrodes and the sample.

From the literature [1-4], it is known that if two solid surfaces are in contact, then the actual contact area is not the projected geometric area but many times smaller. Solids touch only the tops of their protrusions, which are always there even on well-polished surfaces. With an increase in the forces compressing the tissue, these protrusions are crumpled. The contact area increases, which causes a decrease in the measured value of the resistivity of the sample. Point A (see Fig. 1) corresponds to the achievement of the complete contact of 
the electrodes with the sample over the entire geometric area of the sample surface. From this point on, the tissue sample of the fresh apple behaves like a hard elastic body.

In the samples of stale apples, a slight decrease in the value of resistivity, starting from point $\mathrm{B}_{2}$, can be explained by the fact that the protoplasm of some cells, as the pressure increases, dies. First of all, physiologically, older cells die, the resistance of which to force is reduced. This phenomenon is known [16] and is called barroplasmolysis.

Analyzing the nature of the destruction of various samples, starting from point $\mathrm{C}$, it can be concluded that cells in fresh plant tissue are more equivalent in resistance to force than cells in flaccid tissue. Therefore, the destruction of fresh tissue is like the destruction of a fragile body. In flabby tissue, plastic deformation is more developed.

Certain conclusions make it possible to compare the curves for samples of different heights. Thus, for specimens with a height of $5 \mathrm{~mm}$, the resistivity is lower than for specimens with a height of $10 \mathrm{~mm}$, although the general character of the curves before the onset of fracture is the same for them. The nature of their destruction upon reaching critical loads is also significantly different.

This can be explained as follows. When cutting out samples, mechanical damage affects the physiological state of a part of the cells that is not mechanically destroyed. The proportion of such cells in the total volume of a thin sample is greater than that in a tall sample.

For example, consider two samples of different heights but the same diameter (Fig. 2).

They have: $H_{1}=2 H_{2} ; S_{1}=S_{2} ; V_{1}=2 V_{2}$.

When a sample is excised, the surface cells are mechanically damaged, and due to the physiological connection between the cells, this damage also affects the deeper layers of the cells. Let us assume that a layer of cells with a height of $\Delta \mathrm{H}$ corresponds to complete and partial damage. The deeper cells have not changed. The volume occupied by damaged cells at the ends of the samples is

$$
V_{d a m}=2 \cdot \Delta H \cdot S
$$

But since the volume of the first sample is larger than the volume of the second sample, the proportion of damaged cells in the second sample will be greater than in the first one:

$$
\frac{V_{d a m}}{V_{2}-V_{d a m}}>\frac{V_{d a m}}{V_{1}-V_{d a m}}
$$

It is known [8] that the tissue electrical resistance decreases with cell death, and, therefore, the electrical resistivity of the second sample should be lower. It should be emphasized that damaged cells should be understood as those that are completely destroyed and cells whose physiological state was affected by the action of a destructive factor.

Thus, the value of the electrical resistivity of plant tissue depends, among other things, on the height of the sample, or rather on its volume. With an increase in the tissue sample size under study, the error in measuring the true value of electrical conductivity will decrease.

In the actual press extraction process, we have to deal with crushed raw materials and not with large samples of whole plant tissue. The electrical characteristics of the pulp are significantly different from those of the whole tissue. Therefore, along with experiments on samples of whole plant tissue, we studied the electrical conductivity of crushed raw materials. The dependence of electrical conductivity on the degree of grinding, the 
magnitude of the specific pressures on the pulp, and temperature was investigated. The degree of grinding was determined according to the method described in $[5,6,7,8]$.

Experiments were carried out to determine the electrical conductivity of the pulp under static load. For this, chopped carrots were placed in a double-walled measuring cell with graphite electrodes. The preset temperature of the pulp in the cell was maintained with a thermostat with an accuracy of $1{ }^{\circ} \mathrm{C}$. The pressure on the pulp was created with weights. The electrical resistance was measured every 3 minutes for 39 minutes. The bridge circuit, in which the measuring cell was connected, was balanced in terms of the current active component with a resistance box and the reactive component - with a capacitor box.

Experiments have shown that the electrical conductivity of the pulp, under static load and at a constant temperature of $30{ }^{\circ} \mathrm{C}$, increases over time, at first with a high speed and then exponentially. This is graphically shown in Fig. 3.

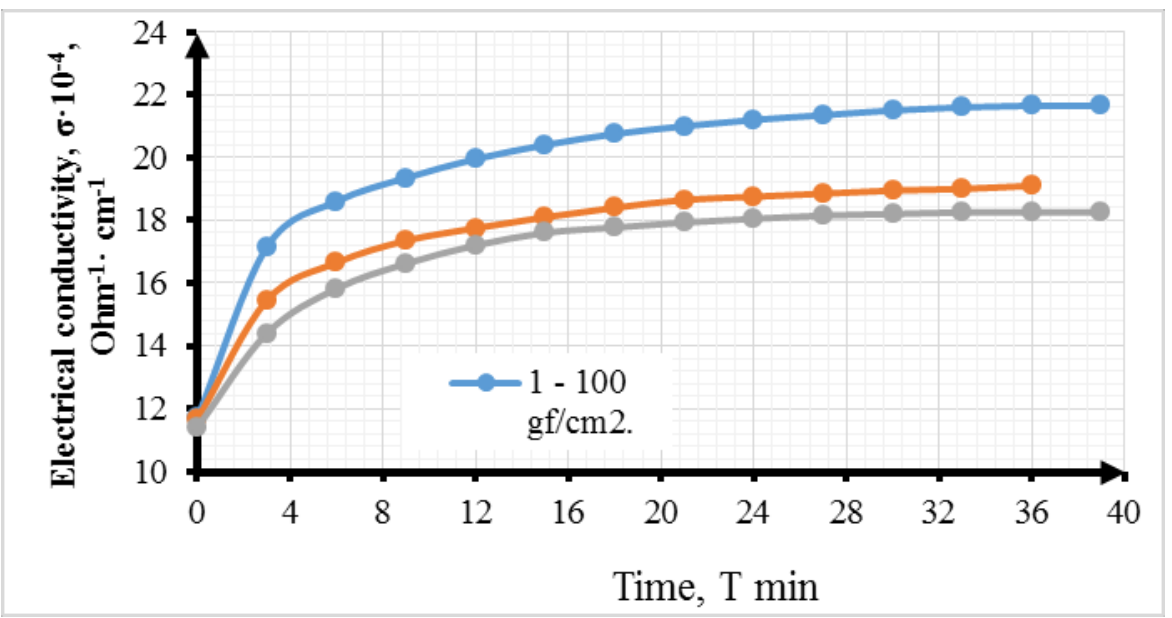

Fig. 3. Dynamics of changes in the value of the electrical conductivity of chopped carrots under static load.

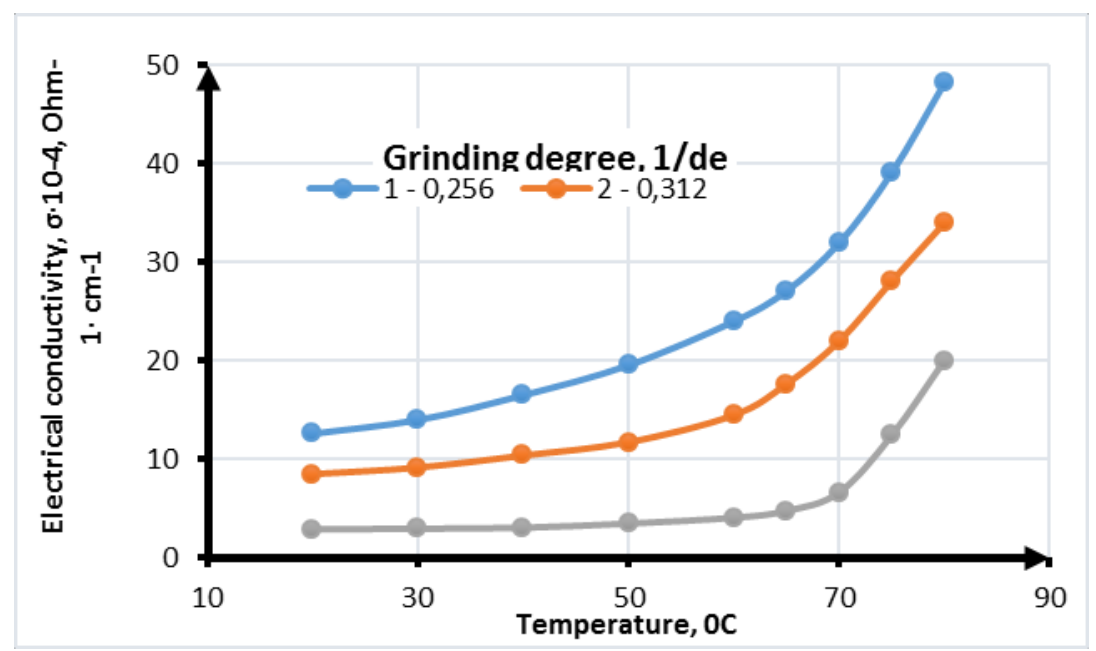

Fig. 4. Dependence of the electrical conductivity of chopped carrots on temperature for three values of the degree of chopping. 
The value of the specific pressure on the pulp is of great importance. Both the rate of rising and the final value of the electrical conductivity of the pulp under given conditions depend on it. Along with these experiments, a series of experiments was carried out to determine the dependence of electrical conductivity on temperature and the degree of grinding of raw materials.

Experiments to determine the temperature dependence of the electrical conductivity of crushed plant tissue were carried out in the following sequence. With certain effective particle diameter, shredded carrots were placed in a measuring cell with graphite electrodes included in one arm of the bridge to measure conductivity. The pulp was compacted with a weight of one kilogram for 5 minutes, after which the load was removed. The electrical conductivity was measured after 5 minutes after reaching the set temperature, which was maintained by the thermostat with an accuracy of $1{ }^{\circ} \mathrm{C}$. The bridge was balanced in terms of the active and reactive components of the electric current.

For comparison, the temperature dependence of the electrical conductivity of carrot juice was determined. Carrot juice was obtained on a juicer. It was poured into the measuring cell, and the $\mathrm{R}$ and $\mathrm{C}$ were measured at different temperatures, which was maintained by the thermostat within the specified limits. The measurements were carried out both by heating the juice from 20 to $80{ }^{\circ} \mathrm{C}$ and by cooling it from 80 to $20{ }^{\circ} \mathrm{C}$. The discrepancies between these measurements did not exceed the experimental error.

The dependence of the electrical conductivity of the pulp on temperature is graphically shown in Fig. 4. It can be seen from the graph that the nature of the change in the electrical conductivity of the pulp changes significantly with the change in the degree of grinding of raw materials. Suppose for the pulp with large particles, the critical point is clearly expressed within $60-65{ }^{\circ} \mathrm{C}$, above which the electrical conductivity begins to increase sharply, then for the pulp with small particles. In that case, the increase in electrical conductivity with temperature is smooth. Here, a faster increase in electrical conductivity occurs, starting from $30{ }^{\circ} \mathrm{C}$, and there is no inflection point. A similar dependence was obtained $[1,3]$ for meat products.

This influence of the degree of plant tissue refinement on the nature of the dependence of electrical conductivity on temperature can be explained as follows. The electrical conductivity of plant tissue, in a rough approximation, consists of the electrical conductivity of the cell sap, the electrical conductivity of the cell membranes, and protoplasm. Cell sap, as an electrolyte, has low electrical resistance, while the resistance of the living protoplasm of cells is many times greater. The determining factor for a whole tissue with intact cells is the resistance of living protoplasm, which is approximately equal to $1 \mathrm{mOhm} . \mathrm{cm}[4,16]$. When cells are damaged (even functional), the electrical resistance of plant tissue decreases [9-13].

With an increase in the degree of grinding, the number of damaged cells increases. The pulp with large particles placed in the measuring cell is a porous body. Electrical contact between the particles is carried out only in the places of their direct contact since the pores in the pulp are large and not filled with juice. As the temperature rises, the conductivity of the pulp slowly increases due to the usual temperature dependence of the conductivity. At a temperature of $60-65{ }^{\circ} \mathrm{C}$, the mass death of cell protoplasm begins. As a result of denaturation changes in colloids, the protoplasm loses its semi-permeable properties, its electrical resistance decreases, and at the same time, juice comes out of the vacuoles. All this leads to an increase in the electrical conductivity of the pulp. In addition, apparently, due to the release of juice and heating, gases are partially removed from the pulp and tissue, the presence of which naturally increases the resistivity of the tissue.

When heating a pulp with a higher degree of grinding, having small particles, the electrical conductivity is mainly determined by the juice that came out of mechanically destroyed cells and filled the small pores of the pulp framework in the cell. It is also 
influenced by the fact that the specific surface area of small particles is greater than that of large ones, which means that the contact area between them is also larger.

From the analysis of the results of these experiments, it can be concluded that in small particles of pulp, a large number of cells are either destroyed or in a state of paranecrosis a state close to complete death. At the same time, it is known that various force effects on the protoplasm of cells are summed up, and the cumulative effect of the stimulus is manifested. Therefore, for the complete destruction of the protoplasm of the surviving cells, lower temperatures are required than for completely undisturbed cells. This conclusion is in good agreement with the results of [14-17].

This means that a part of the cells remains intact during cleavage and the presence of connective tissues and cell membranes significantly impairs the electrical conductivity of the crushed pulp compared to the electrical conductivity of pure juice. The difference by order of magnitude in the magnitude of the electrical conductivity of the pulp and juice at a temperature of $80^{\circ} \mathrm{C}$ suggests that there is no complete contact between the pulp particles, the continuity of the pulped body in the cell is broken. This is also confirmed by the data graphically presented in Figure 5.

In the actual pressing process, the porous body of the pulp is simultaneously compressed and the juice removed from it. The study of such a process is a difficult task because its course is influenced by a large number of variables that are not always amenable to accurate accounting. This process is still insufficiently studied. There are only a few works $[1,2]$ by the Hungarian scientist Imre Kormendi, in which the first attempt was made to give a general theory of the process of pressing the pulp of plant materials.

We studied the dependences of the magnitude of the specific electrical resistance and the volume occupied by the pulp on the pressing time and specific pressures on the pulp while taking into account the amount of pressed juice.

The experiments were carried out on pulp of varying degrees of grinding. The pressure was raised in steps, simulating the real production cycle of the batch press. The resistance was measured at a frequency of $1000 \mathrm{~Hz}$ according to the method described above. The volume occupied by the pulp was calculated, taking into account the magnitude of its deformation under pressure. In this series, experiments were repeated six times for each value of the degree of pulp grinding.

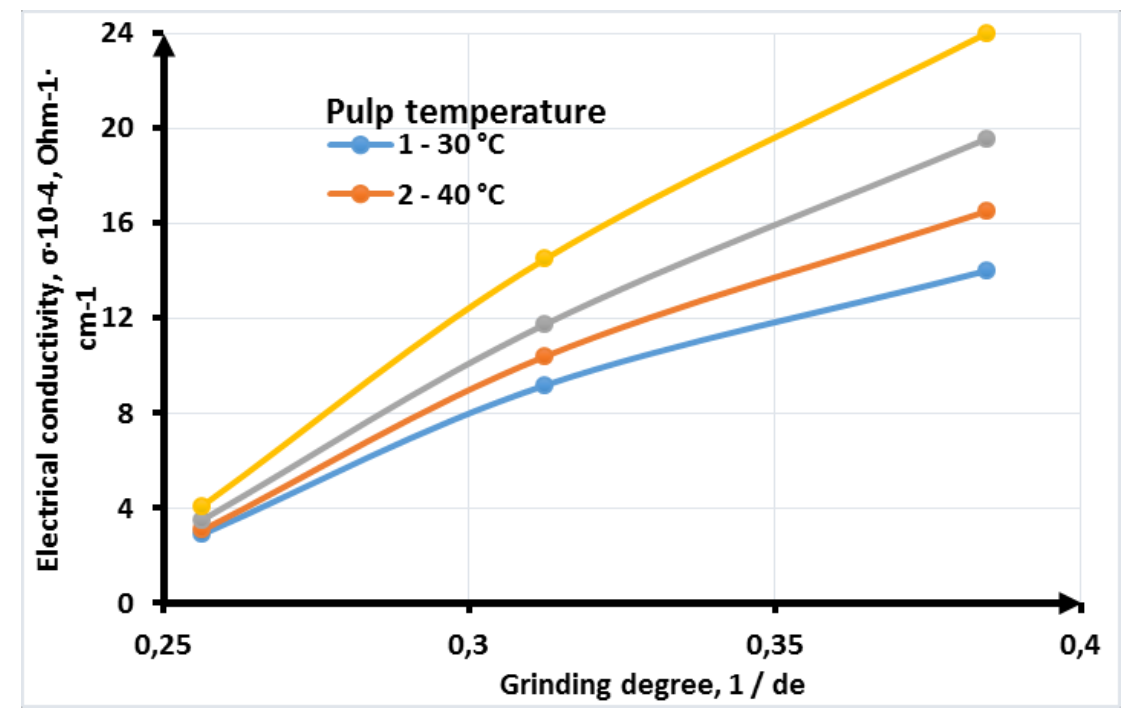

Fig. 5. Dependence of the electrical conductivity of chopped carrots on the degree of chopping 
For fine pulp, it is characteristic that the resistance changes almost along a straight line with a slight slope to the abscissa axis. The volume occupied by the pulp of varying degrees of grinding, with sufficient compaction, changes insignificantly. Therefore, a significant change in the value of electrical resistance is associated with a change in the contact resistance between the particles.

Based on the analysis of the study results, an electrical circuit for replacing the pressed pulp was drawn up, shown in Figure 6.

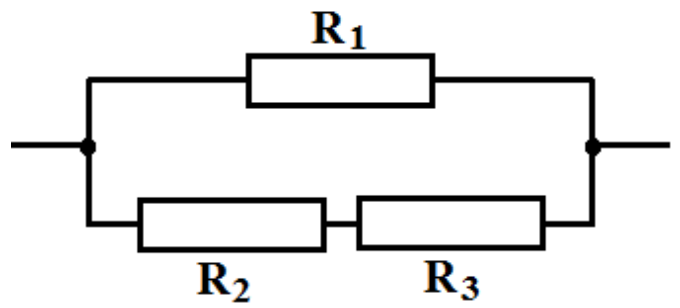

Fig. 6. Replacement diagram of the pressed pulp (designations in the text)

Here: $\mathrm{R}_{1}$ is juice resistance, $\mathrm{Ohm}$.

$\mathrm{R}_{2}$ is plant tissue resistance, Ohm.

$\mathrm{R}_{3}$ is contact resistance between particles of pulp, Ohm.

The equivalent resistance of this circuit is:

and the current

$$
R_{\text {equi }}=\frac{R_{1}\left(R_{2}+R_{3}\right)}{R_{1}+R_{2}+R_{3}}
$$

$$
I=I_{1}+I_{2}
$$

As the juice comes out in the process of pressing, $\mathrm{R}_{1}$ will increase, and therefore the current in the second chain with $\left(\mathrm{R}_{2}+\mathrm{R}_{3}\right)$ should increase. This will be facilitated by a decrease in $\mathrm{R}_{3}$, due to improved contact between particles. Thus, the effectiveness of the effect of electric current on plant tissue will increase as the pulp is compacted and the juice is drained from it.

Summing up the study of the electrical conductivity of whole and crushed plant tissue, it can be noted that various factors have a strong influence on its value and the nature of the change: temperature, pressure, degree of grinding, the physiological state of the tissue and its cells.

\section{Conclusions}

1. It has been proven that with axial compression of plant tissue, the measured value of specific electrical resistance decreases due to improved contact between electrodes and tissue. This casts doubt on the hypothesis of complete internal contact of cells and elimination of intercellular glands during tissue compression, which is the basis of the theory of electroplasmolysis under pressure.

2. The magnitude and nature of changes in the electrical conductivity of whole and crushed plant tissue are strongly influenced by temperature, pressure, degree of grinding, the physiological state of the tissue and its cells. At a temperature of 60-65 ${ }^{\circ} \mathrm{C}$, denaturation changes in protoplasm occur in living cells of large particles of the pulp, leading to a sharp increase in the magnitude of the electrical conductivity of the pulp. As the juice content in the pulp decreases, its electrical resistance increases. 


\section{References}

1. Bazhal M.I., Vorobiev E.I. Electrical treatment of apple slices for intensifying juice pressing // J. Sci. Food Agric. V.80. pp.1668 - 1674. (2000).

2. Beveridge T. Juice extraction from apples and other fruits and vegetables. Critical Rev. Food Sci. Nutr. V.37(5). pp.449 - 469. (1997).

3. Bazhal M.I., Lebovka N.I., Vorobiev E.I. Pulsed electric field treatment of apple tissue during compression for juice extraction // J. Food Eng. V.50(3). pp.129 - 139. (2001).

4. Rojas A.M., Castro M.A., Alzamora S.M., Gershenson L.N. Turgor pressure effects on textural behaviour of honeydew melon // J. Food Sci. V.66(1). pp.111 - 117. (2001).

5. Ibragimov M., Eshpulatov N., Matchanov O.Q., Nuraliyev S. Statics and kinetics of decreasing the moisture content of technical seeds. International Journal of Advanced Research in Science, Engineering and Technology Vol. 7, Issue 2, February (2020).

6. Sayfutdinov R.S., Mukhitdinov U.D., Eshpulatov N. Increasing Reactivity Cotton Cellulose Intended For Acetylation. International Journal of Research. Volume 07. Issue 04.- P. 854-860. April (2020).

7. Sayfutdinov R.S., Mukhitdinov U.D., Eshpulatov N.M. (2020) Research of increasing the reactivity cotton cellulose intended for chemistry. Technical science and innovation: Vol. (2020): Iss.1, Article 10. Available at: https://uzjournals.edu.uz/btstu/vol2020/iss1/10

8. Radjabov A., Ibragimov M., Eshpulatov N.M., Matchonov, O. Improving the energy performance of ozone generators used in agricultural ecology. Journal of Physics: Conference Series. Volume 1399, Issue 5, 5 055060. December (2019).

9. Radjabov, A., Berdishev, A.S., Mussabekov, A.T. Autonomous Complex for Water Disinfection in Rural Areas of Uzbekistan. Applied Solar Energy (English translation of Geliotekhnika). Volume 55, Issue 2, 1 pp.113-118. March (2019).

10. Ibragimov M., Eshpulatov N., Matchanov O. Electrical technology of moisture content reduction of industrial-grade cotton seeds. IOP Conference Series: Materials Science and Engineering. 883(1), 012135. (2020).

11. Sayfutdinov R.S., Mukhitdinov U.D., Eshpulatov N.M. Increasing reactivity of cotton celluloses for chemical processing. IOP Conference Series: Materials Science and Engineering. 883(1), 012133. (2020).

12. Eshpulatov N.M., Salomov M.N., Fayzullaev B.P. Energy characteristics in artificial energy systems. Actual problems of agricultural science, production and education. Voronezh,- pp. 142-144. April 15, (2016).

13. Yusubaliev A. Electric sorting in cotton growing: monograph / A. Yusubaliev; Tashkent Institute of Irrigation and Agricultural Mechanization Engineers. Novosibirsk: Akademizdat, -p. 176. (2019).

14. Bayzakova J.S., Abdildin N.K., Shynybay Zh.S., Chingenzhinova Zh.S., Berdyshev A.S., Eshpulatov N.M., Matchonov O.Q., Yusupov Sh.B. Methodology for conducting an optimization experiment for harvesting dry short-stalked grain crops. IOP Conf. Series: Earth and Environmental Science. 614 (2020) 012118.

15. Ibragimov M., Eshpulatov N., Matchanov O. Substantiation of the optimal parameters by processing with electric contact methods to decrease the moisture content of technical seeds. IOP Conf. Series: Earth and Environmental Science. 614 (2020) 012018 . 
16. Radjabov A., Ibragimov M., Eshpulatov N. The study of the electrical conductivity of Apples and Grapes as an object of electrical processing. E3S Web of Conferences, (2021), 226, 00002.

17. Choriev J., Muslimov T., Abduraupov R, Khalimbetov A., Abdurakhmonov S. Fundamentals of developing and designing portable weirs for farmlands. IOP Conf. Series: Materials Science and Engineering. 869 (2020) 072023. 